\title{
Effect of manganese ion on the mineralization of 2,4-dichlorophenol by ozone
}

\author{
Hua Xiao ${ }^{\mathrm{a}, \mathrm{b}}$, Ruiping Liu ${ }^{\mathrm{a}}, \mathrm{Xu}_{\mathrm{Zhao}}{ }^{\mathrm{a}}$, Jiuhui $\mathrm{Qu}{ }^{\mathrm{a}, *}$ \\ a State Key Laboratory of Environmental Aquatic Chemistry, Research Center for Eco-Environmental Sciences, Chinese Academy of Sciences, Beijing 100085, China \\ ${ }^{\mathrm{b}}$ Graduate School of Chinese Academy of Sciences, Beijing 100039, China
}

\section{A R T I C L E I N F O}

\section{Article history:}

Received 9 January 2008

Received in revised form 9 April 2008

Accepted 10 April 2008

Available online 3 June 2008

\section{Keywords:}

Catalytic ozonation

$\mathrm{Mn}^{2+}$

Hydroxyl radicals

GC-MS

Intermediates

\begin{abstract}
A B S T R A C T
Mineralization of 2,4-dichlorophenol (DCP) was studied by ozone with $\mathrm{Mn}^{2+}$ as an ozonation catalyst. Laboratory scale semi-batch ozonation experiments were conducted at room temperature. The results showed that trace amount of $\mathrm{Mn}^{2+}$ accelerated the mineralization of DCP. Total organic carbon removal rate was independent on $\mathrm{Mn}^{2+}$ dosage at its range of $0.1-0.5 \mathrm{mg} \mathrm{L}^{-1}$. Dissolved ozone concentration in the solution remained low level in the catalytic ozonation process, which indicated that $\mathrm{Mn}^{2+}$ catalyzed decomposition of ozone. DCP mineralization was inhibited in catalytic ozonation by the addition of carbonate. Electron spin resonance/spin-trapping technique was used to determine hydroxyl radicals, and the results showed that larger amounts of hydroxyl radicals were produced in catalytic ozonation system than those of single ozonation. Intermediates mainly including aliphatic carboxylic acids were determined qualitatively and semi-quantitatively by GC-MS. And, a general pathway for mineralization of DCP was proposed.
\end{abstract}

(c) 2008 Elsevier Ltd. All rights reserved.

\section{Introduction}

Chlorophenols have been widely used in the production of wood preservatives, pesticides, and other industrial chemicals (Verschueren, 1983). They also formed as by-products during bleaching of pulp with chlorine and in chlorination of drinking water (Ahlborg and Thunberg, 1980). Because of their numerous origins, they can be found in drinking water and industrial wastewaters. Several of them which are toxic and thereby harmful to public health and aquatic life, such as 2,4-dichlorophenol (DCP), have been listed among the 127 priority pollutants by the USA EPA (Keith and Telliard, 1979).

Catalytic ozonation, which combines a transition metal with ozone to degrade organic pollutants, has been received extensive interests in recent two decades. Cortes et al. (2000) investigated ozonation of chlorobenzene by using $\mathrm{Fe}^{2+}$ and $\mathrm{Mn}^{2+}$ as catalysts, and they reported that the addition of $6 \times 10^{-5} \mathrm{M}$ metallic ions improved the overall efficiency of ozonation. The study by Matheswaran et al. (2007) showed that Ce(III)-catalytic ozonation increased degradation rate of phenol comparing to uncatalyzed ozonation and a maximum total organic carbon (TOC) removal was obtained in the former case. Ni et al. (2003) studied the ozonation of 2-chlorophenol solution with the addition of various kinds of metallic

\footnotetext{
* Corresponding author. Tel.: +86 10 62849151; fax: +86 1062923558 .

E-mail addresses: jhqu@rcees.ac.cn, hjliu@rcees.ac.cn (J. Qu).
}

ions, including $\mathrm{Pb}^{+}, \mathrm{Cu}^{2+}, \mathrm{Zn}^{2+}, \mathrm{Fe}^{2+}, \mathrm{Ti}^{2+}$, and $\mathrm{Mn}^{2+}$. It was found that the reaction rate increased in all cases, and the best result was obtained by using $\mathrm{Mn}^{2+}$. Okawa et al. (2005) also reported that the degradation rate for 2,4-DCP by ozone in acetic acid was greatly enhanced in addition of $\mathrm{Fe}^{3+}$ or $\mathrm{Mn}^{2+}$. These studies suggested that catalytic ozonation had strong ability to degrade refractory organics in water solution. In the present investigation, mineralization of DCP was studied using catalytic ozonation with $\mathrm{Mn}^{2+}$ as the catalyst.

\section{Experimental}

\subsection{Materials}

DCP (99.9\%) was used as a model compound for catalytic ozonation. It was purchased from Beijing Chemical Co. (Beijing, China). A stock solution of $400 \mathrm{mg} \mathrm{L}^{-1}$ was prepared by dissolving DCP into deionized water, and was further diluted to $10 \mathrm{mg} \mathrm{L}^{-1}$ with deionized water before use. Ozone was produced from pure oxygen using the "corona discharge" method in a laboratory ozonator (MITSUBISHI OZONIZER, OS-n, JAPAN). $\mathrm{MnSO}_{4} \cdot \mathrm{H}_{2} \mathrm{O}$ was dissolved in deionized water to produce a stock solution containing $200 \mathrm{mg} \mathrm{L}^{-1}$ of $\mathrm{Mn}^{2+}$. Methanol of HPLC grade was purchased from Fisher Company. 5,5-dimethyl-1-pyrroline- $N$-oxide (DMPO) was from Aldrich. Other reagents such as sodium thiosulphate, potassium iodide, potassium indigo trisulfonate, etc., were used without further purification. All glassware was soaked in chromic acid, then rinsed with tap water and deionized water. 


\subsection{Ozonation procedure}

The catalytic ozonation experiments were carried out in a $2.5 \mathrm{~L}$ glass reactor at room temperature $\left(25^{\circ} \mathrm{C}\right)$ in a semi-batch mode. The aqueous solution of substrates was placed into the reactor before starting the reaction. The $\mathrm{pH}$ was adjusted with sulfuric acid and sodium hydroxide $(0.1 \mathrm{M})$. Then, $\mathrm{Mn}^{2+}$ was introduced, and the reaction was initiated by bubbling the ozone/oxygen mixture. The solution was continuously stirred with a magnetic bar. Ozone gas was bubbled continuously into $2.0 \mathrm{~L}$ of reaction mixture through a porous glass membrane at the bottom of the reactor for $30 \mathrm{~min}$. Ozone gas-flow rate and concentration were controlled at $200 \mathrm{~mL} \mathrm{~min}^{-1}$ and $8.2+0.3 \mathrm{mg} \mathrm{L}^{-1}$, respectively. The residual ozone in the off-gas was absorbed by KI solution. The samples were withdrawn from the outlet at regular intervals and the oxidation reaction was quenched by adding a small amount of sodium thiosulphate. Samples were stored at $4{ }^{\circ} \mathrm{C}$ and were analyzed within $24 \mathrm{~h}$.

\subsection{Electron spin resonance (ESR) procedure}

ESR experiment was applied to determine hydroxyl radicals generated in ozonation process by using a nitron spin-trapping reagent DMPO. In ozone-saturated aqueous solution containing DCP and $\mathrm{Mn}^{2+}, 1.0 \mathrm{mM}$ of DMPO was added under vigorous agitation. After the addition of DMPO, $25 \mu \mathrm{L}$ of the sample solution was transferred into a capillary tube immediately. ESR spectra was recorded in the X-band on a Bruker electron spin resonance ESP 300E. ESR measurements were conducted at room temperature under the following conditions: modulation amplitude $2 \mathrm{G}$; microwave power of $10 \mathrm{~mW}$; modulation frequency $100 \mathrm{kHz}$; sweep width $100 \mathrm{G}$; receiver gain $1.00 \mathrm{e}+005$.

\subsection{Analysis}

Aqueous dissolved ozone concentration was determined by using the indigo method (Bader and Hoigne, 1981). The adsorption measurements were performed at $600 \mathrm{~nm}$ on a U-3010 UV-Vis spectrophotometer (Hitachi, Japan). The ozone concentration in the gas was measured with iodometric method (APHA, 1992) before the ozone was introduced into the reactor. The concentration of TOC was analyzed using a multi N/C 3000 TOC analyzer (Analyti kjena AG, Germany). The pH was measured using Thermo Orion model 410 (Thermo Orion, USA). The meter was calibrated daily with National Institute of Standards and Technology buffers of pH 4.01 and pH 7.00. DCP concentration was analyzed by reversed-phase HPLC with a Hitachi HPLC apparatus (Diode Array Detector L-2450, Column Oven L-2300, and Pump L-2130). An Allsphere ODS-25u column (Alltech, USA), $250 \mathrm{~mm} \times 46 \mathrm{~mm}$, was used and the column temperature was $40^{\circ} \mathrm{C}$. The mobile phase was a mixture of 70:30 methanol/water containing $1 \%$ acetic acid. The injection volume was $20 \mu \mathrm{L}$, the flow rate was $1.0 \mathrm{~mL} \mathrm{~min}^{-1}$ and the wavelength of the UV absorbance detector was $280 \mathrm{~nm}$. Under these conditions, the retention time of DCP was $4.1 \mathrm{~min}$. $\mathrm{Cl}^{-}$concentration in water was measured using an ion chromatogram (Metrohm 861 advanced compact IC) equipped with a conductivity detector and a 250/4.0 mm column (Metrosep A Supp 4, Metrohm). The eluent was $1.8 \mathrm{mM} \mathrm{Na}_{2} \mathrm{CO}_{3}$ and $1.7 \mathrm{mM} \mathrm{NaHCO}$ solution. The samples were filtered through $0.22 \mu \mathrm{m}$ filter to determine $\mathrm{Mn}^{2+}$ concentration in solution by ICP method (SCIEX Perkin Elmer Elan mode 5000). Samples for GC-MS analysis were prepared by the following procedure. The samples were filtered to remove particles through $0.45 \mu \mathrm{m}$ filter. The solution was evaporated by freeze-dried method. The residue was dissolved in $5 \mathrm{~mL}$ methylene chloride, and derivatized with $0.1 \mathrm{~mL} \mathrm{N,O-bis(trimethyl-}$ silyl)trifluoroacetamide and trimethylchlorosilane for $30 \mathrm{~min}$ at
$60{ }^{\circ} \mathrm{C}$. Then the sample was dried with $\mathrm{Na}_{2} \mathrm{SO}_{4}$ and concentrated to $1 \mathrm{~mL}$ to be analyzed. GC-MS analysis was carried out on an Agilent 7890GC/5975MSD with a HP-5 MS capillary column. The column was used with the following temperature procedure: $80^{\circ} \mathrm{C}$ hold for $6 \mathrm{~min}$, ramp at $4{ }^{\circ} \mathrm{C} \mathrm{min}-1$ to $180^{\circ} \mathrm{C}$, $180^{\circ} \mathrm{C}$ hold for $10 \mathrm{~min}$. The injector port was at $280^{\circ} \mathrm{C}$, and the carrier gas was helium.

\section{Results and discussion}

\subsection{Effect of $\mathrm{Mn}^{2+}$ dose on mineralization of $D C P$}

Firstly, degradation of DCP was compared between the catalytic and non-catalytic ozonation. Fig. 1a presents the results of DCP degradation and TOC removal in these two processes. As can be seen from Fig. 1a, the efficiency of DCP degradation was slightly higher in catalytic ozonation than that in single ozonation, and these two processes led to about 100\% DCP degradation in $10 \mathrm{~min}$; however, catalytic ozonation led to more than $80 \%$ TOC removal and single ozonation only allowed for less than $40 \%$ in $30 \mathrm{~min}$, that is to say, catalytic ozonation had much more mineralization capacity on DCP than single ozonation.

DCP is characterized by hydroxyl substituent and the hydroxyl group activates the electrophilic reaction through which ozone reacts directly with aromatic compounds, so the direct reaction between DCP and ozone contributes greatly to the degradation of DCP. As observed from Fig. 1a, it can be speculated that the mineralization of DCP could be generally divided into two stages: ozonation of DCP and mineralization of intermediates. At the first stage of reaction, most ozone led into the solution reacted directly with

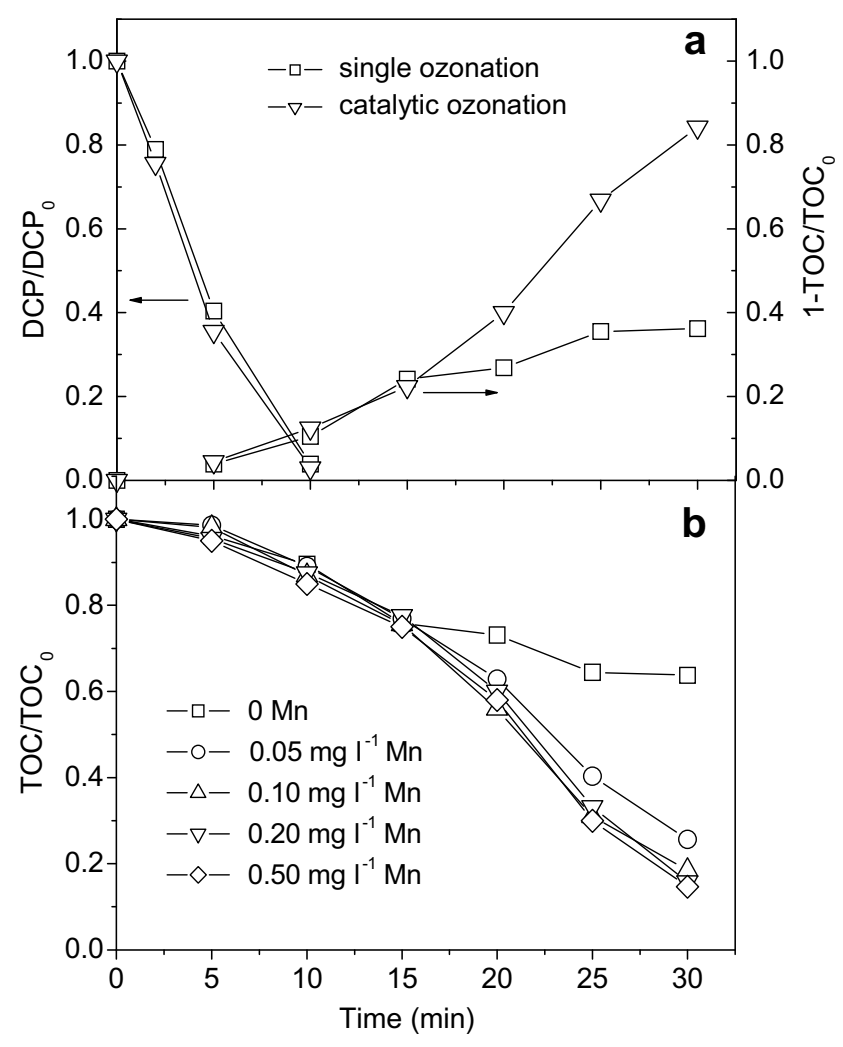

Fig. 1. DCP degradation and TOC removal with time corresponding to single and catalytic ozonation (a) and Effect of $\mathrm{Mn}^{2+}$ concentration on TOC removal in catalytic ozonation (b). Conditions: $T=25^{\circ} \mathrm{C}$, initial pH 5.5, initial DCP concentration $=10.0 \mathrm{mg} \mathrm{L}^{-1}$, ozone gas concentration $=8.4 \mathrm{mg} \mathrm{L}^{-1}$, ozone mixture gas flow $=200 \mathrm{ml} \mathrm{min}^{-1}$. 
DCP and only a small portion of ozone reacted with intermediate products. With the progress of reaction, increasing amount of intermediates was produced from the ozonation of DCP, and they were further mineralized at the later stage of reaction. According to the above two-stage reaction process, the transformation of DCP is achieved at the first stage and the removal of TOC is accomplished mainly at the second stage.

The addition of $\mathrm{Mn}^{2+}$ significantly promoted mineralization of DCP by ozone, and then the activity of $\mathrm{Mn}^{2+}$ was investigated by conducting an experimental series at different $\mathrm{Mn}^{2+}$ loads in the range of $0-0.5 \mathrm{mg} \mathrm{L}^{-1}$. As shown in Fig. $1 \mathrm{~b}$, mineralization of DCP is rather limited without catalyst, but it is greatly improved in the presence of $\mathrm{Mn}^{2+}$. Catalytic ozonation with $0.05 \mathrm{mg} \mathrm{L}^{-1} \mathrm{Mn}^{2+}$ has much higher TOC removal efficiency than single ozonation. The effect of increasing $\mathrm{Mn}^{2+}$ is clearly noticed up to a value of $0.1 \mathrm{mg} \mathrm{L}^{-1}$, and catalytic ozonation with $0.1 \mathrm{mg} \mathrm{L}^{-1} \mathrm{Mn}^{2+}$ allows about $80 \%$ TOC removal in $30 \mathrm{~min}$. However, further increasing catalyst amount to 0.2 or $0.5 \mathrm{mg} \mathrm{L}^{-1}$ does not yield much increase of the TOC removal. It can be concluded that the presence of $\mathrm{Mn}^{2+}$ is very important to enhance mineralization of intermediates, and a little of $\mathrm{Mn}^{2+}$ such as $0.1 \mathrm{mg} \mathrm{L}^{-1}$ was enough to ensure a strong catalytic effect.

\subsection{Mechanism of ozonation catalyzed by $\mathrm{Mn}^{2+}$}

\subsubsection{Evolution of dissolved ozone concentration and $\mathrm{Mn}^{2+}$ concentration}

To further clarify why $\mathrm{Mn}^{2+}$ accelerated mineralization of DCP, dissolved ozone concentration in single ozonation, catalytic ozonation and blank experiment was investigated. The blank experiment was conducted with $\mathrm{Mn}^{2+}$ and ozone but in the absence of

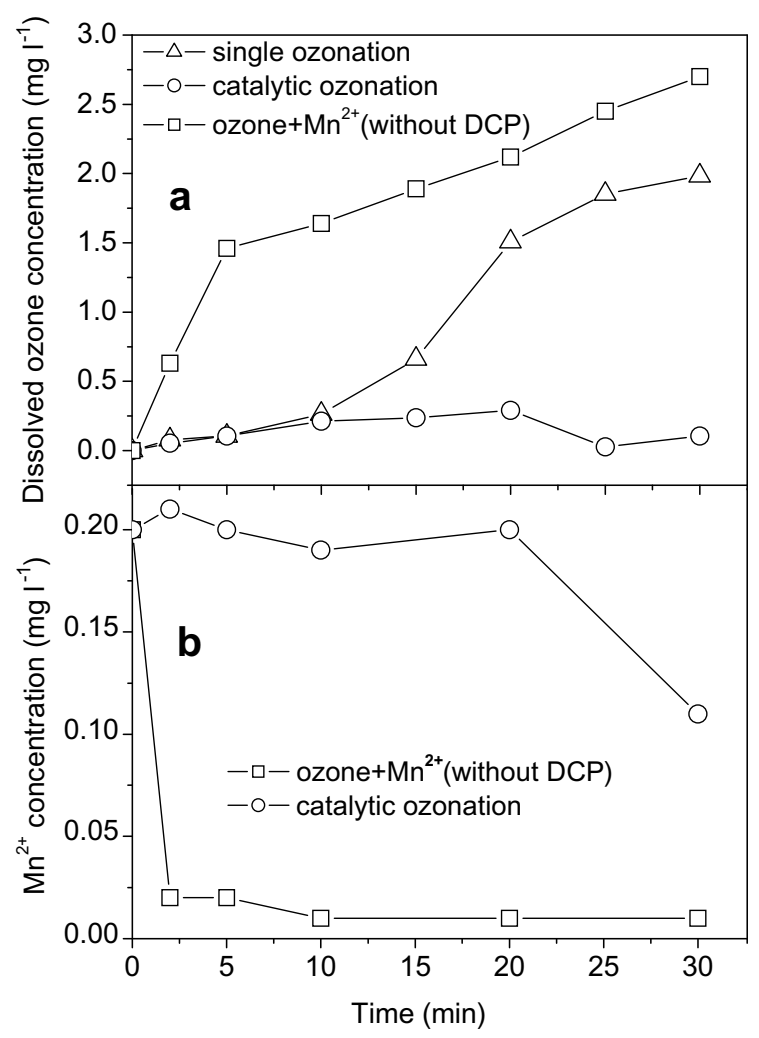

Fig. 2. Evolution of dissolved ozone concentration (a) and $\mathrm{Mn}^{2+}$ concentration (b) with time in several systems. Conditions: $T=25^{\circ} \mathrm{C}$, initial pH 5.5, initial DCP concentration $=10 \mathrm{mg} \mathrm{L}^{-1}, \mathrm{Mn}^{2+}$ concentration $=0.2 \mathrm{mg} \mathrm{L}^{-1}$, ozone gas concentration $=8.4 \mathrm{mg} \mathrm{L}^{-1}$, ozone mixture gas flow $=200 \mathrm{ml} \mathrm{min}^{-1}$.

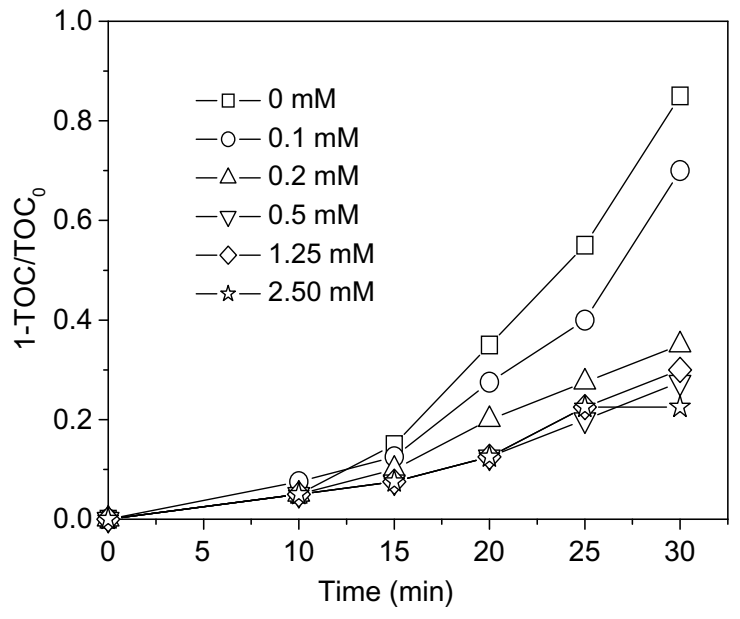

Fig. 3. Effect of carbonate concentration on TOC removal in catalytic ozonation Conditions: $T=25{ }^{\circ} \mathrm{C}$, initial DCP concentration $=10 \mathrm{mg} \mathrm{L}^{-1}, \mathrm{Mn}^{2+}$ concentration $=0.2 \mathrm{mg} \mathrm{L}^{-1}$, ozone gas concentration $=8.4 \mathrm{mg} \mathrm{L}^{-1}$, ozone mixture gas flow $=200 \mathrm{ml} \mathrm{min}^{-1}$.

DCP. Fig. 2a shows evolution of dissolved ozone concentration with time in the above three systems. During all the three processes, dissolved ozone was detected in the solution after $2 \mathrm{~min}$. Dissolved ozone gradually accumulated in single ozonation and blank experiment, and their concentration reached about 2.0 and $2.7 \mathrm{mg} \mathrm{L}^{-1}$ at $30 \mathrm{~min}$, respectively. From Fig. $2 \mathrm{a}$ it was also stated that during the former $10 \mathrm{~min}$ of single ozonation dissolved ozone accumulation rate was relatively slower, but during the later $20 \mathrm{~min}$, dissolved ozone accumulation rate increased sharply and its concentration reached a higher level. During the initial $10 \mathrm{~min}$, the reaction between ozone and DCP consumed a great deal of dissolved ozone, and in 10 min oxidation DCP was transformed into organic intermediates which are relatively difficult to be oxidized by ozone. By contrast, in catalytic ozonation, dissolved ozone concentration

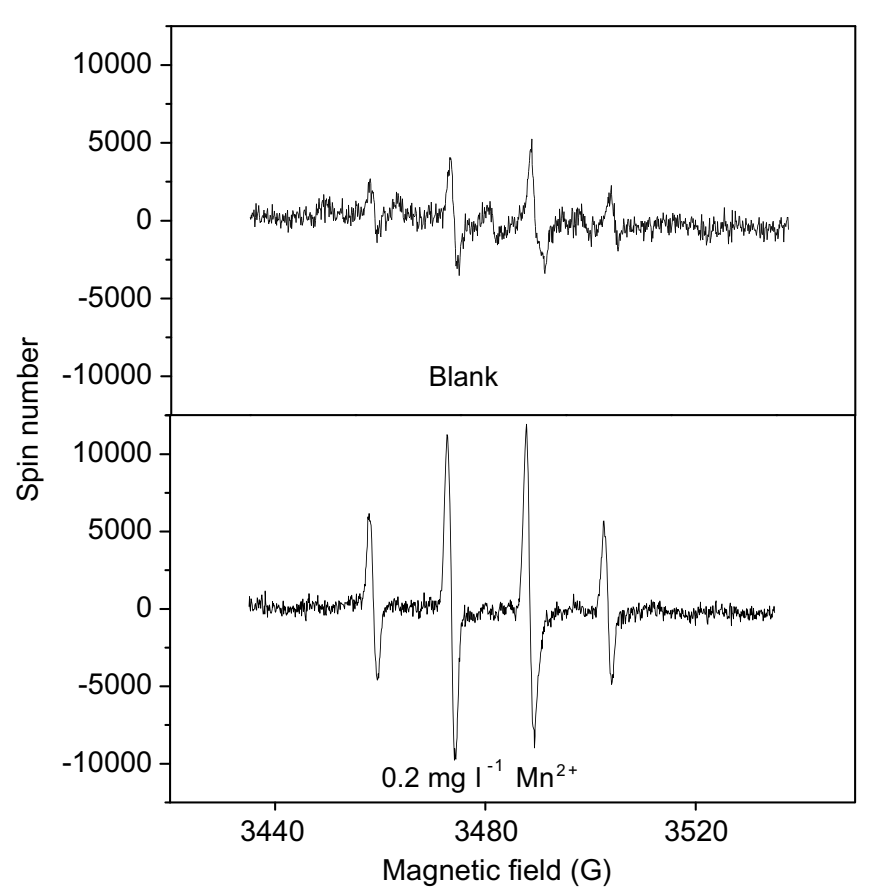

Fig. 4. ESR spectrum corresponding to blank and catalytic ozonation. Conditions: DCP concentration $=10 \mathrm{mg} \mathrm{L}^{-1}$, DMPO concentration $=0.1 \mathrm{mM}$. 
Table 1

Main intermediates detected by GC-MS in the single and catalytic ozonation of DCP

\begin{tabular}{|c|c|c|c|c|c|}
\hline \multirow[t]{2}{*}{ Retention time (min) } & \multirow[t]{2}{*}{ Intermediates } & \multirow[t]{2}{*}{ Molecular structure } & \multicolumn{3}{|c|}{ Peak area $\left(\times 10^{6}\right)$} \\
\hline & & & $10 \mathrm{~min}$ & $20 \mathrm{~min}$ & $30 \mathrm{~min}$ \\
\hline 10.70 & Oxalic acid & $\mathrm{O}$ & $\begin{array}{l}4.3^{\mathrm{a}} \\
9.9^{\mathrm{b}}\end{array}$ & $\begin{array}{l}158.9^{\mathrm{a}} \\
206.6^{\mathrm{b}}\end{array}$ & $\begin{array}{r}64.1^{\mathrm{a}} \\
213.8^{\mathrm{b}}\end{array}$ \\
\hline 13.50 & Propanedioic acid & $\mathrm{O}$ & $\begin{array}{l}N^{a} \\
N^{b}\end{array}$ & $\begin{array}{l}N^{a} \\
N D^{b}\end{array}$ & $\begin{array}{l}35.2^{\mathrm{a}} \\
\mathrm{ND}^{\mathrm{b}}\end{array}$ \\
\hline 14.17 & Maleic anhydride & $\mathrm{O}$ & $\begin{array}{l}22.3^{a} \\
28.3^{b}\end{array}$ & $\begin{array}{l}30.1^{\mathrm{a}} \\
\mathrm{ND}^{\mathrm{b}}\end{array}$ & $\begin{array}{l}\mathrm{ND}^{\mathrm{a}} \\
\mathrm{ND}^{\mathrm{b}}\end{array}$ \\
\hline 16.37 & Glycerol & $\mathrm{OH}$ & $\begin{array}{l}\mathrm{ND}^{\mathrm{a}} \\
8.7^{\mathrm{b}}\end{array}$ & $\begin{array}{l}\mathrm{ND}^{\mathrm{a}} \\
\quad 24.1^{\mathrm{b}}\end{array}$ & $\begin{array}{r}8.2^{\mathrm{a}} \\
14.7^{\mathrm{b}}\end{array}$ \\
\hline 17.20 & Maleic acid & & $\begin{array}{l}66.5^{\mathrm{a}} \\
\mathrm{ND}^{\mathrm{b}}\end{array}$ & $\begin{array}{l}N^{a} \\
N D^{b}\end{array}$ & $\begin{array}{l}\mathrm{ND}^{\mathrm{a}} \\
\mathrm{ND}^{\mathrm{b}}\end{array}$ \\
\hline 17.50 & Butanedioic acid & & $\begin{array}{l}28.3^{a} \\
48.5^{b}\end{array}$ & $\mathrm{ND}^{\mathrm{b}}$ & $\begin{array}{l}12.8^{\mathrm{a}} \\
\mathrm{ND}^{\mathrm{b}}\end{array}$ \\
\hline 18.67 & Fumaric acid & & $\begin{array}{l}N^{a} \\
40.8^{b}\end{array}$ & $\begin{array}{l}N^{a} \\
N D^{b}\end{array}$ & $\begin{array}{l}\mathrm{ND}^{\mathrm{a}} \\
\mathrm{ND}^{\mathrm{b}}\end{array}$ \\
\hline 20.60 & 2-hydroxy- propanedioic acid & & $\begin{array}{l}43.7^{\mathrm{a}} \\
91.5^{\mathrm{b}}\end{array}$ & $\begin{array}{r}903.2^{\mathrm{a}} \\
1225.3^{\mathrm{b}}\end{array}$ & $\begin{array}{l}291.5^{\mathrm{a}} \\
698.7^{\mathrm{b}}\end{array}$ \\
\hline 21.61 & 2-hydroxy-2- propenoic acid & & $\begin{array}{l}\mathrm{ND}^{\mathrm{a}} \\
\mathrm{ND}^{\mathrm{b}}\end{array}$ & $\begin{array}{l}\mathrm{ND}^{\mathrm{a}} \\
\quad 26.8^{\mathrm{b}}\end{array}$ & $\begin{array}{l}14.2^{\mathrm{a}} \\
\mathrm{ND}^{\mathrm{b}}\end{array}$ \\
\hline 27.09 & 2,3-dihydroxyl- succinic acid & & $\begin{array}{l}14.2^{\mathrm{a}} \\
26.4^{\mathrm{b}}\end{array}$ & $\begin{array}{l}169.9^{\mathrm{a}} \\
192.3^{\mathrm{b}}\end{array}$ & $\begin{array}{l}16.9^{\mathrm{a}} \\
92.7^{\mathrm{b}}\end{array}$ \\
\hline
\end{tabular}


Table 1 (continued)

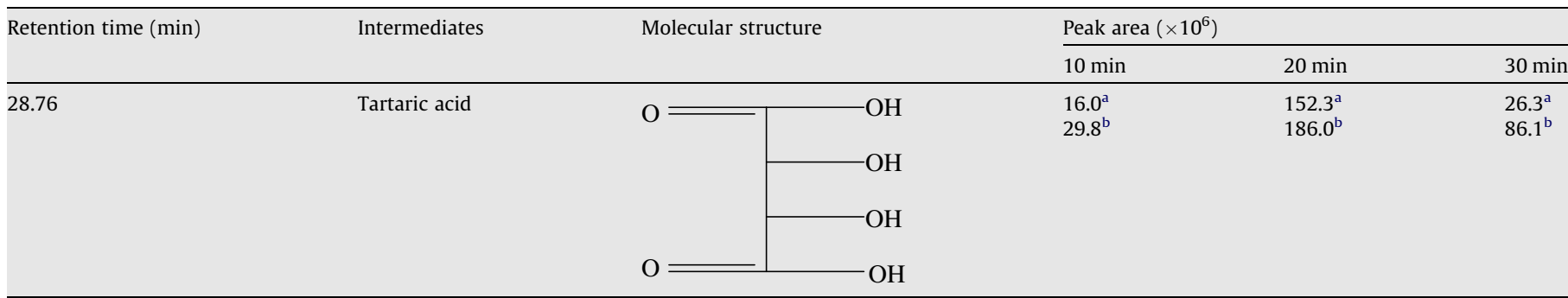

ND - not detected.

a Catalytic ozonation.

b Single ozonation.

always remained low level, and its maximum value was less than $0.3 \mathrm{mg} \mathrm{L}^{-1}$. These results suggested that the presence of $\mathrm{Mn}^{2+} \mathrm{did}$ enhance dissolved ozone decomposition rate and led to the low concentration of dissolved ozone in catalytic ozonation process.

Soon after the reaction of $\mathrm{Mn}^{2+}$ (without DCP) and ozone, the solution quickly became brown, which is the color of the colloid of $\mathrm{MnO}_{2}$. But there is no color change during the initial $25 \mathrm{~min}$ of catalytic ozonation process. Then the concentration of $\mathrm{Mn}^{2+}$ was also determined in catalytic ozonation and blank experiment. As shown in Fig. 2b, the concentration of $\mathrm{Mn}^{2+}$ quickly reduced to $0.02 \mathrm{mg} \mathrm{L}^{-1}$, which showed that $\mathrm{Mn}^{2+}$ was rapidly oxidized into $\mathrm{MnO}_{2}$ by ozone in blank experiment. However, in catalytic ozonation of DCP, $\mathrm{Mn}^{2+}$ concentration remained constant in $25 \mathrm{~min}$, and then decreased to $0.11 \mathrm{mg} \mathrm{L}^{-1}$ at $30 \mathrm{~min}$. Manganese maintained dissolved ion status in $25 \mathrm{~min}$ of reaction in catalytic ozonation, then a little amount of insoluble $\mathrm{MnO}_{2}$ was produced by ozone in the last $5 \mathrm{~min}$. Referring to the results of TOC removal in Fig. 1a, it was found that the presence of $\mathrm{Mn}^{2+}$ accelerated the mineralization of DCP, and meanwhile manganese existed as the status of ion in the presence of plenty of organics; $\mathrm{Mn}^{2+}$ was oxidized into $\mathrm{MnO}_{2}$ when organics in solution were almost completely mineralized. Based on above analysis, it may be proposed that $\mathrm{Mn}^{2+}$ was the catalyst of ozonation of DCP.

\subsubsection{Effect of carbonate on mineralization of $D C P$}

Ozone is a powerful oxidant, but it does not cause complete mineralization of organic acids owing to its selective oxidation. Hydroxyl radical is more effective oxidant without selectivity. It is well-known that carbonate is radical scavenger (Hoigne and Bader,

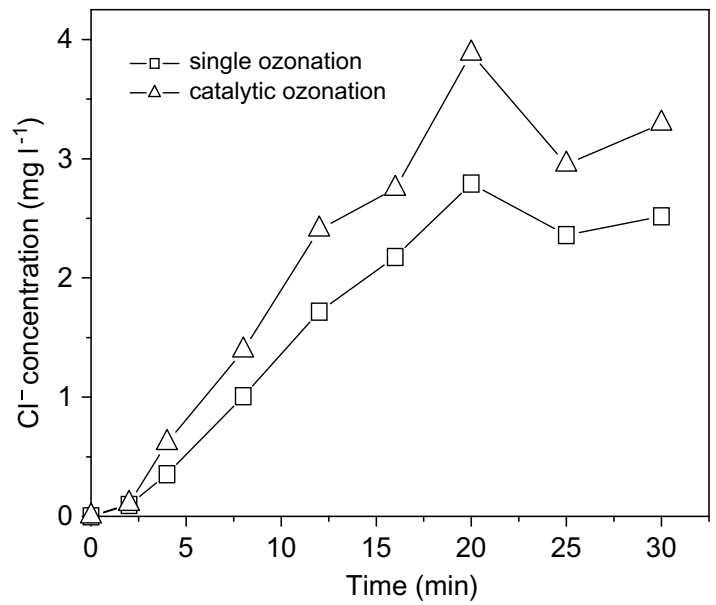

Fig. 5. Evolution of chloride ion concentration with time in single and catalytic ozonation. Conditions: $T=25^{\circ} \mathrm{C}$, initial pH 5.5, initial DCP concentration $=10 \mathrm{mg} \mathrm{L}^{-1}, \quad \mathrm{Mn}^{2+}$ concentration $=0.2 \mathrm{mg} \mathrm{L}^{-1}$, ozone gas concentration $=8.4 \mathrm{mg} \mathrm{L}^{-1}$, ozone mixture gas flow $=200 \mathrm{ml} \mathrm{min}^{-1}$.
1985), which has a strong quenching effect on hydroxyl radical reaction $\left(\mathrm{KcO}_{3}^{2-}=3.9 \times 10^{8} \mathrm{M}^{-1} \mathrm{~s}^{-1}\right)$ (Acero and von Gunten, 2000). Thus, the effect of carbonate on the mineralization of DCP was tested in order to identify the role of hydroxyl radicals in catalytic ozonation. It can be seen from Fig. 3 that the addition of $0.1 \mathrm{mM}$ carbonate obviously reduced the mineralization rate of DCP. And, at the carbonate concentration of $0.5 \mathrm{mM}$, DCP mineralization was largely inhibited and only $30 \%$ TOC was removed within $30 \mathrm{~min}$. These results confirmed that hydroxyl radicals played a dominant role in mineralization of $\mathrm{DCP}$ by $\mathrm{Mn}(\mathrm{II})$-catalytic ozonation.

\subsubsection{Generation of hydroxyl radicals}

According to above experiment result, it was known that dissolved ozone decomposed much faster in catalytic ozonation than in single ozonation, and the addition of carbonate greatly inhibited TOC removal in catalytic ozonation. So it was necessary to know

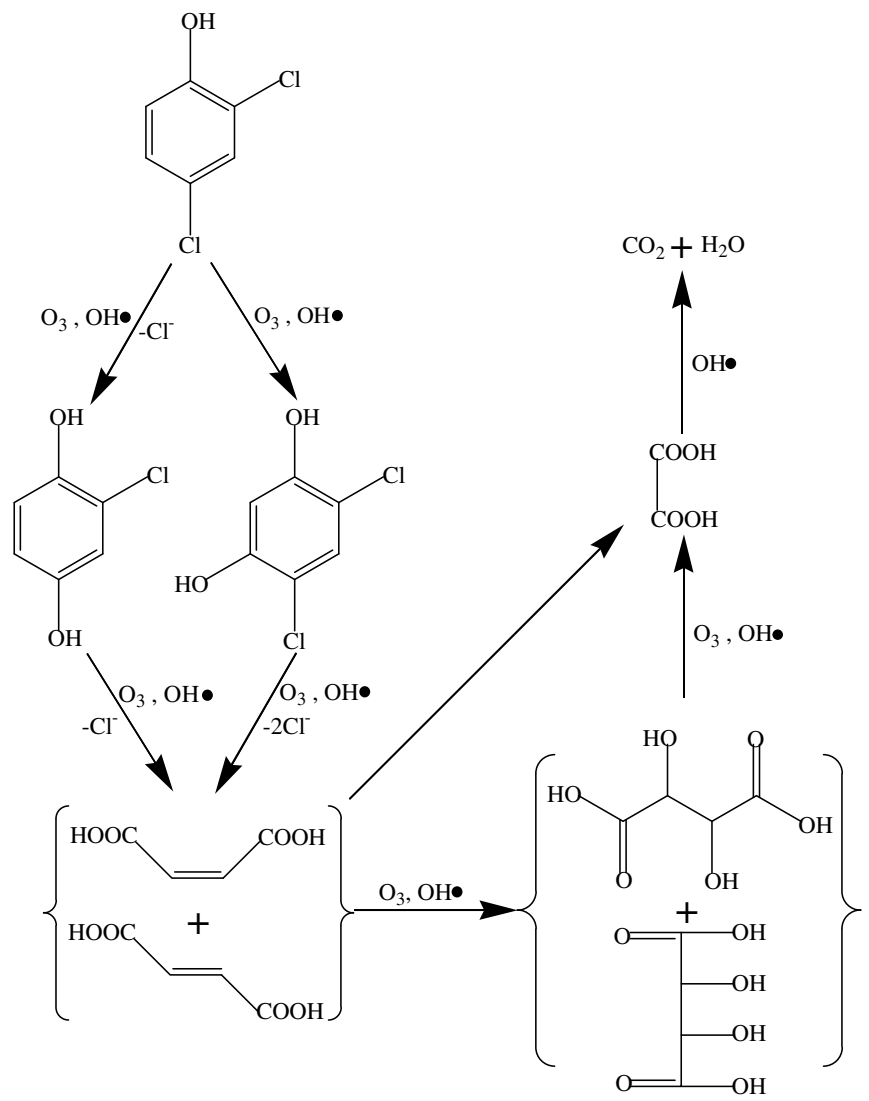

Fig. 6. General reaction pathway proposed for mineralization of DCP by ozone and hydroxyl radicals in single and catalytic ozonation. 
whether much more hydroxyl radicals were produced in the presence of $\mathrm{Mn}^{2+}$. In order to detect free radicals, ESR spectroscopy is utilized because of its sensitivity and selectivity, and ESR/spintrapping technique has been developed to detect unstable radicals (Janzen and Blackburn, 1969). Hydroxyl radical is moderately reactive and hence typically transient, making its detection difficult on an ESR time scale. Thus DMPO was used as a spin-trap reagent to trap hydroxyl radical. When hydroxyl radical is formed in the presence of DMPO, it is trapped to form stable paramagnetic nitroxyl radical adduct DMPO-OH, which can be observed in ESR spectra (Takahashi et al., 2007). In the present study, hydroxyl radicals were determined qualitatively and semi-quantitatively. Fig. 4b shows the typical ESR spectrum obtained after mixing aqueous ozone with DMPO solution added by $\mathrm{Mn}^{2+}$ and DCP. The spectrum was composed of quartet lines having peak height ratio of $1: 2: 2: 1$. The ESR parameters coincided with those of typical DMPO-OH adduct (Utsumi et al., 1994). The signal strength of DMPO-OH adduct represents the amount of $\mathrm{OH}$ radical to some extent during ozonation. Comparing the results in Figs. $4 \mathrm{a}$ and $\mathrm{b}$, a much stronger signal of DMPO-OH was presented in catalytic ozonation than that in uncatalyzed process, which indicated that more hydroxyl radicals were produced when $\mathrm{Mn}^{2+}$ was used as catalyst in ozonation process. Thus, the greater mineralization rate of DCP in the presence of $\mathrm{Mn}^{2+}$ could be attributed to an increase of hydroxyl radical concentration.

\subsection{Intermediates produced in ozonation processes}

\subsubsection{Identification of organic products by GC-MS}

Organic products corresponding to different reaction times were measured by GC-MS. Three samples at 10, 20 and $30 \mathrm{~min}$ were withdrawn to be analyzed in single ozonation and catalytic ozonation, respectively. Table 1 depicts the detailed products information. As shown in the Table, many organic intermediates were produced in ozonation of DCP, and the main products included the aliphatic acids such as oxalic acid, 2-hydroxy-propanedioic acid, 2,3-dihydroxysuccinic acid, tartaric acid, and so on; in addition, small quantity of other intermediates were produced, for example, maleic anhydride, glycerol, and pyruvic acid. The peak area was used to estimate the products semi-quantatively. Generally, by comparing the results in Table 1, it was also suggested that the quantities of products in catalytic ozonation were much less than those at the same reaction time in single ozonation. From Table 1 it was generally found that in catalytic ozonation process most intermediates accumulated gradually at the early reaction stage, then were further degraded or disappeared at the later stage, but propanedioic acid, glycerol, and 2-hydroxy-2-propenoic acid were only produced at the later reaction stage. All intermediates except oxalic acid had experienced the same changing trend in the single ozonation, and gradual accumulation of oxalic acid showed that it was relatively difficult to be degraded in the single ozonation. According to above results, catalytic ozonation had much higher ability to degrade intermediates than single ozonation, which also explained the phenomenon that TOC removal was higher in catalytic ozonation than that in single ozonation.

\subsubsection{Production of chloride ion: Dechlorination}

With the oxidation of DCP, the chloride atoms break off from phenyl ring to be formed into chloride ions. The evolution of chloride ion in single ozonation and catalytic ozonation is shown in Fig. 5. Catalytic ozonation led to $88 \%$ chloride conversion in $20 \mathrm{~min}$; single ozonation only allows for $64 \%$ conversion. During the later $10 \mathrm{~min}$ of reaction, chloride ion concentration decreased to some extent in these two processes, which may be due to active chlorine formation by ozonation of chloride ion (Le Roy Brough Yeatts and Taube, 1949).

\subsection{Proposed reaction pathway}

Based on the results of intermediates analysis, it was suggested that DCP experienced similar mineralization process in single ozonation and catalytic ozonation. Referring to published work (Brillas et al., 2003), a general pathway for the ozonation of DCP is proposed in Fig. 6.

The process is initiated by the hydroxylation of DCP yielding chlorohydroquinone or 4,6-dichlororesorcinol (Brillas et al., 2003) with loss of a chloride atom. Further degradation of chlorobenzoquinone and 4,6-dichlororesorcinol by reaction with ozone or $\mathrm{OH}$ produced maleic and fumaric acids. They can be degraded in consecutive steps to produce a mixture of 2,3-hydroxy-succinic acid and tartaric acids, which are converted into oxalic acid. The transformation of all carboxylic acids into oxalic acid is accelerated as more $\mathrm{OH}$ is generated in the medium by catalytic ozonation. Oxalic acid remains relatively stable in single ozonation system, but it can be converted into carbon dioxide by ${ }^{\circ} \mathrm{OH}$ in catalytic ozonation system finally.

\section{Conclusions}

$\mathrm{Mn}^{2+}$ has effective catalytic activity in the ozonation process. Although the degradation rates of DCP were almost the same in the catalyzed and uncatalyzed ozonation process, the addition of $0.2 \mathrm{mg} \mathrm{L}^{-1} \mathrm{Mn}^{2+}$ in the ozonation of DCP increased the TOC removal efficiency from $40 \%$ to $80 \%$.

$\mathrm{Mn}^{2+}$ promoted decomposition of ozone in catalytic ozonation of DCP, so dissolved ozone concentration kept low level in the reaction. The addition of carbonate had negative effect on TOC removal in catalytic ozonation process. ESR experiments confirmed that larger amounts of $\mathrm{OH}$ radicals generated when $\mathrm{Mn}^{2+}$ was applied. Some short-chain organic acids were detected by GC-MS in the ozonation of DCP, and fewer amounts of organic byproducts were produced in catalytic ozonation than those of single ozonation. Oxalic acid was produced as the ultimate organic product in the ozonation of DCP, and it remained relatively stable in single ozonation but it can be further oxidized into carbon dioxide in catalytic ozonation. The production of chloride ion in catalytic ozonation was more than that in single ozonation.

\section{Acknowledgments}

This work was supported by the Funds for Creative Research Groups of China (Grant No. 50621804) and by National Natural Science Foundation of China (Grant No. 50538090).

\section{References}

Acero, J.L., von Gunten, U., 2000. Influence of carbonate on the ozone/hydrogen peroxide based advanced oxidation process for drinking water treatment. Ozone Sci. Eng. 22, 305-328.

Ahlborg, U.G., Thunberg, T.M., 1980. Chlorinated phenols: occurrence, toxicity, metabolism and environmental impact. Crit. Rev. Toxicol. 7, 1-35.

APHA, 1992. Standard Methods for the Examination of Water and Wastewater. American Public Health Association, Washington, DC.

Bader, H., Hoigne, J., 1981. Determination of ozone in water by the indigo method. Water Res. 15, 449-456.

Brillas, E., Calpe, J.C., Cabot, P., 2003. Degradation of the herbicide 2,4dichlorophenoxyacetic acid by ozonation catalyzed with $\mathrm{Fe}^{2+}$ and UVA light. Appl. Catal. B 46, 381-391.

Cortes, S., Sarasa, J., Ormad, P., Gracia, R., Ovelleiro, J.L., 2000. Comparative efficiency of the systems $\mathrm{O}_{3} /$ high $\mathrm{pH}$ and $\mathrm{O}_{3} /$ catalyst for the oxidation of chlorobenzenes in water. Ozone Sci. Eng. 22, 415-426.

Hoigne, J., Bader, H., 1985. Rate constants of reactions of ozone with organic and inorganic compounds in water III: inorganic compounds and radicals.. Water Res. 19, 993-1004.

Janzen, E.G., Blackburn, B.J., 1969. Detection and identification of short-lived free radicals by an electron spin resonance trapping techniques (spin trapping) 
Photolysis of organolead, -tin and mercury compounds. J. Am. Chem. Soc. 91, 4481-4490.

Keith, L.H., Telliard, W.A., 1979. Priority pollutants: a prospective view. Environ. Sci. Technol. 13, 416-424.

Le Roy Brough Yeatts, J., Taube, $\mathrm{H}$., 1949. The kinetics of the reaction of ozone and chloride ion in acid aqueous solution. J. Am. Chem. Soc. 71, 4100-4105.

Matheswaran, M., Balaji, S., Chung, S.J., Moon, I.S., 2007. Studies on cerium oxidation in catalytic ozonation process: a novel approach for organic mineralization. Catal. Commun. 8, 1497-1501.

Ni, C.H., Chen, J.N., Yang, P.Y., 2003. Catalytic ozonation of 2-dichlorophenol by metallic ions. Water Sci. Technol. 47 (1), 77-82.
Okawa, K., Tsai, T.Y., Nakano, Y., Nishijima, W., Okada, M., 2005. Effect of metal ions on decomposition of chlorinated organic substances by ozonation in acetic acid. Chemosphere 58, 523-527.

Takahashi, M., Chiba, K., Li, P., 2007. Formation of hydroxyl radicals by collapsing ozone microbubbles under strongly acidic conditions. J. Phys. Chem. B 111, 11443-11446.

Utsumi, H., Hakoda, M., Shimbara, S., Nagaoka, H., Chung, Y., Hamada, A., 1994 Active oxygen species generated during chlorination and ozonation. Water. Sci. Technol. 30 (9), 91-99.

Verschueren, K., 1983. Handbook of Environmental Data on Organic Chemicals. Van Nostrand Reinhold, New York. 